\title{
Aufwendig illustrierte Vulgata
}

Bei der in diesem Jahr in virtueller Form durchgeführten Stuttgarter Antiquariatsmesse gelang die Erwerbung einer bemerkenswerten Bibelausgabe (Ba graph.1574 81). Es handelt sich um eine Neuausgabe der erstmals 1547 erschienenen sog. Löwener Vulgata (Bb lat.1547 01). Der belgische Ordenstheologe Johannes Hentenius (ca. 1500-1566) strebte eine textgeschichtlich möglichst authentische und zugleich mit der Tradition des kirchlichen Lehramtes konforme Edition der Vulgata an. Dies geschah in Reaktion auf die verwirrende Vielfalt neuer, auch lateinischer Bibelausgaben seit der Reformation. Dazu zog er die besten verfügbaren Druckausgaben sowie zwanzig Handschriften der Vulgata heran, lehnte aber im Falle von Abweichungen anders als viele humanistisch beeinflusste Gelehrte eine Korrektur vom hebräischen bzw. griechischen Urtext her ab.

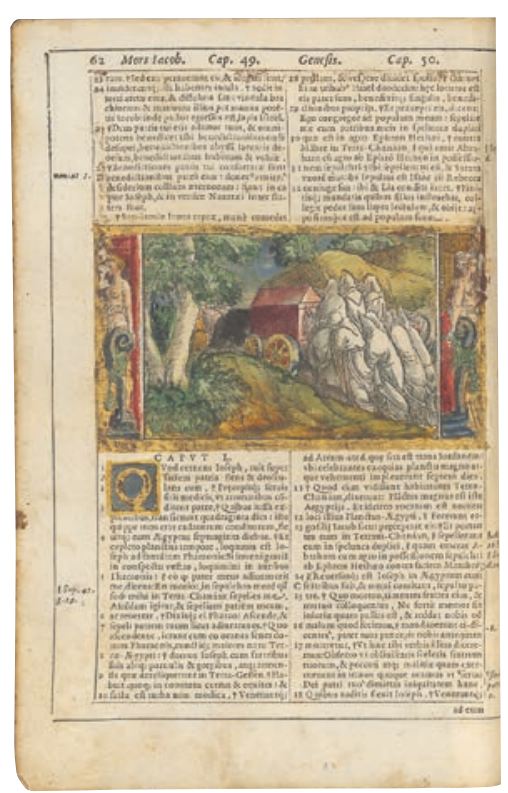

Abb. 1-2: Ende des Buches Genesis (Ba graph.1574 81)
Die Besonderheit dieser Ausgabe liegt aber weniger im Text- als im Bildanteil. Auf 1150 Seiten wurden etwa 600 kleinformatige Textholzschnitte präsentiert. Hinzu kommen Holzschnitt-Initialen an allen Kapitel-Anfängen. Kaum eine Seite der zweispaltig mit humanistischer Antiqua gedruckten Ausgabe blieb frei von Illustrationen; manche Seiten weisen sogar bis zu vier Holzschnitte auf. Man kann davon ausgehen, dass es sich um einen italihandelte, der von der Offizin Bevilacqua mit der Bildkonzeption beauftragt wurde. Von Format und

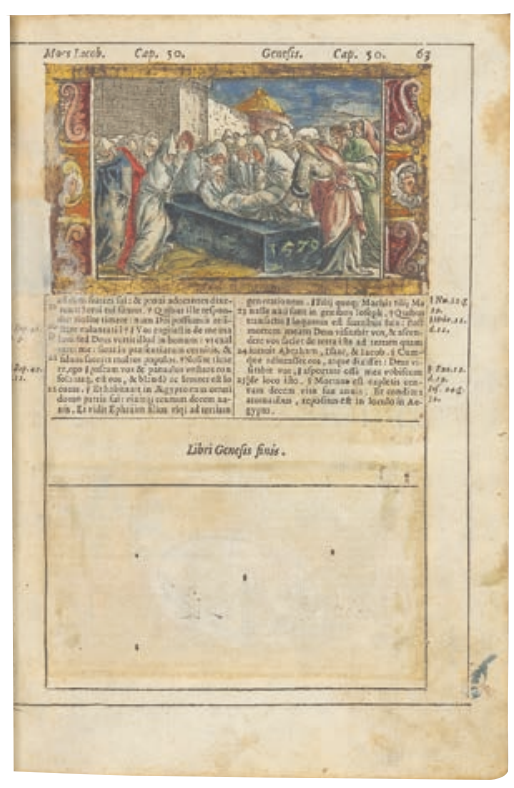

Gesamtkomposition her ähnliche Illustrations-Reihen waren v.a. aus französischen Ausgaben mit Bildern von Hans Holbein dem Jüngeren (1497-1543; z.B. B graph. 1550 01), Pierre Eskrich (1530-1590; z.B. B graph.1577 01) und Bernard Salomon (ca. 1506-1561; z.B. B graph.1559 01) bekannt. Sie weienischen, wahrscheinlich venezianischen Künstler

Seine sozusagen genuin lateinische Version wurde mehrmals verbessert und nachgedruckt und bildete eine wesentliche Grundlage für die dann lange Zeit maßgebliche Fassung der Vulgata, die Sixto-Clementina (1590/1592). Die Erben des venezianischen Druckers Niccolò Bevilacqua nutzten 1574, also ein Jahr nach dessen Tod, den Textstand der Löwener Vulgata für die auf das KleinQuart-Format verkleinerte und ausgiebig illustrierte Ausgabe. Sie unterstrichen damit ihren Anspruch auf Fortführung der bedeutenden Druckertradition ihrer Familie, kooperierten bei dieser Publikation allerdings mit dem erfahrenen venezianischen Drucker Altobello Salicato (ca. 1545-1609). chen im Detail aber motivisch so stark ab, dass es sich bei den Holzschnitten der Bevilacqua-Bibel trotz Anklängen an diese zeitgenössischen Bilder nicht um bloße Nachschnitte handelt. Im Stil der Renaissance wurden die Holzschnitte durch Bordüren mit antikisierenden Figuren an den Satzspiegel angepasst. Für das 16. Jahrhundert ungewöhnlich ist die ausführliche Illustrierung der Evangelien, die darin den anderen erzählenden Textpartien der Bibel nicht nachstehen. Dadurch kam vielleicht eine bewusste Abgrenzung gegenüber der Reformation zum Ausdruck. Luther befürchtete, dass die Illustration einzelner Szenen zur Lektüre nur der illustrierten Textpassagen führen könnte, wo 
doch gerade bei den Evangelien die Rezeption des gesamten Textes als wichtig erschien. Deswegen enthielten zumal volkssprachliche Bibeln in reformatorischer Tradition bis zum frühen 17. Jahrhundert zunächst allenfalls Evangelisten-Bilder, meist aber keine Illustrationen zu einzelnen Evangelientexten. In der vorliegenden venezianischen Ausgabe wurde auch auf polemische bzw. kontroverstheologische Spitzen in der Illustration, etwa zur Johannes-Apokalypse, verzichtet. sefs (Genesis 50,26) knüpft etwa bei der Kleidung an das Brauchtum im Italien des 16. Jahrhunderts an. Ähnliches gilt mit Bezug auf die Architektur z.B. für die komplexe Bilderfolge zu den Plagen, von denen die Ägypter so lange betroffen waren, bis sie die von ihnen versklavten Israeliten ziehen ließen (Exodus 7-11).

Das erworbene Exemplar stammt ursprünglich aus dem Besitz des allerdings erst 1634 gegründeten Piaristen-Kollegs im mährischen Leipnik

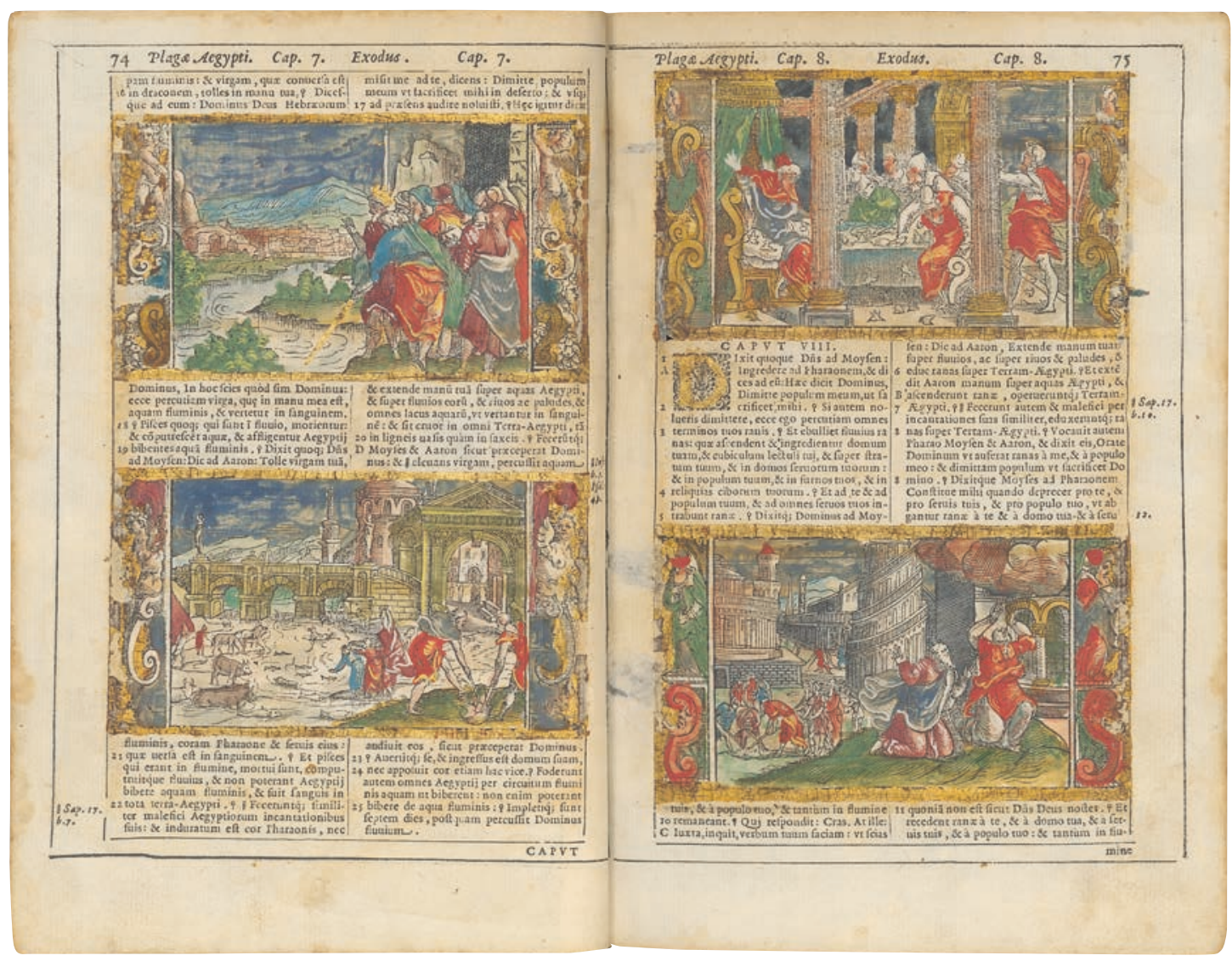

(Lipník). Ein weiterer, teilweise schwer leserlicher Eintrag nennt eine Einzelperson, die wohl im Zusammenhang mit dem Kloster stand. Die blindgeprägten Verzierungen des Kalbsleder-Einbandes weisen, ohne dass sich die Werkstatt exakt bestimmen ließe, mit Motivik und Stil in den süddeutschen bzw. habsburgischen Raum (z.B. Platten mit Justitia bzw. mit dem gekreuzigten Christus und Mose sowie Johannes den Täufer). Man kann davon ausgehen, dass
Abb. 3: Plagen Ägyptens (Ba graph. 1574 81)

Die Wirkung der Fülle an Holzschnitten wird unterstützt durch die filigrane Kolorierung bzw. Ausstattung mit Blattgold. So erscheinen die Figuren in einer dynamischen Lebendigkeit. Am Ende der Genesis vermerkte der Buchmaler auf dem Sarg Josefs das Jahr 1579. Die Kolorierung erfolgte also im Auftrag des ersten Besitzers fünf Jahre nach der Drucklegung. Die Darstellung des Trauerzugs für Jakob (Genesis 50,7-9) und der Grablegung Jo- der venezianische Druck in ungebundenem oder interimistisch gebundenem Zustand in die großen Handelsstädte des deutschen Sprachraums gelangte, dort erworben und im Auftrag des nicht näher bekannten ersten Eigentümers gebunden sowie koloriert wurde; zudem wurde der Schnitt punziert. Häufig kamen solche Bände durch Stiftungen später in den Besitz von Klöstern und von dort meist im 19. Jahrhundert in staatliche oder private Sammlungen. 